\title{
The evaluation of asecond line drug susceptibilities and molecular epidemiological profiles of multidrug resistance Mycobacterium tuberculosis isolates isoleted from different region of Turkey
}

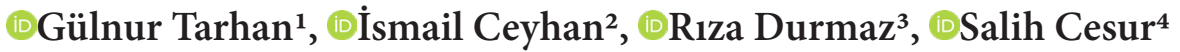 \\ ${ }^{1}$ Adıyaman University, Faculty of Medicine, Department of Medical Microbiology, Adiyaman, Turkey \\ ${ }^{2}$ Yıldırım Beyazit University, Faculty of Health Sciences, Department of Nursing, Ankara, Turkey \\ ${ }^{3}$ Ylldırım Beyazıt University, Faculty of Medicine, Department of Medical Microbiology, Ankara, Turkey \\ ${ }^{4}$ University of Health Sciences, Ankara Training and Research Hospital, Clinic of Infectious Diseases and Clinical Microbiology, Ankara, Turkey
}

Cite this article as: Tarhan G, Ceylan I, Durmaz R, Cesur S. The evaluation of asecond line drug susceptibilities and molecular epidemiological profiles of multidrug resistance Mycobacterium tuberculosis isolates isoleted from different region of Turkey. Anatolian Curr Med J 2022; 4(1); 81-88.

\begin{abstract}
Introduction: This study was planned to determine the second line drug resistance and molecular epidemiological profiles of multidrug resistant Mycobacterium tuberculosis isolates isolated from different geographical regions of Turkey.

Material and Method: In our study, 63 MDR M. tuberculosis isolates were evaluated for the drug susceptibility sent from different tuberculosis laboratories of Turkey. Secondary antituberculosis drugs resistance was evaluated by indirect proportion method. Epidemiological origins were evaluated by using IS6110-RFLP and spoligotyping methods.

Results: Cycloserine, ethionamide, capreomycin, thiacetozone, ofloxacin, kanamsin and paraaminosalicylic acid resistance rates were $15.87 \%, 19.04 \%, 7.93 \%, 6.34 \%, 11.11 \%, 12.69 \%$ and $6.34 . \%$, respectively. According to spoligotyping results, 11 different patterns were obtained, including 52 isolates consisting of 5 clusters and 11 patterns consisting of a single isolate. When we compared our results with the spoligotype database in the world; 42 of 52 isolates forming 5 clusters were identified as predefined spoligotypes (LAM7-TUR, LAM9, T clade). 10 isolates showed the characteristics of the U spoligotype family. Of the 11 isolates that produced 11 different patterns, 8 were Haarlem and T spoligotypes. It was found that 2 isolates had the characteristics of Orphan and 1 isolate had the characteristics of BOV family.

Conclusion: In our study, LAM7-TUR, LAM9, T clade spoligotype families are common in our country and in the world were determined.
\end{abstract}

Keywords: M. tuberculosis, multi-drug resistance, IS6110 RFLP, spoligotyping

\section{INTRODUCTION}

Tuberculosis (TB) is one of the most common infectious diseases worldwide. Approximately 1.5 billion people worldwide are infected with TB bacilli, 10 million new cases occur each year and 3 million people die from $\mathrm{TB}$ (1). Development of multiple drug resistance (MDR) to TB drugs is a major problem worldwide. Multidrug-resistant tuberculosis (MDR-TB) is called TB caused by strains of Mycobacterium. M. tuberculosis (MTB) resistant to INH and RIF. It is man-made and is considered to be the heaviest form of resistant TB because resistance to the two most effective drugs of treatment develops (2-4). The MDR-TB problem has been experienced in developing countries where inadequate treatment programs have been implemented for years.
In recent years, it has been observed in developed countries due to HIV prevalence. Second line drugs should be added to the treatment. Factors in the development of second line drug resistance are the education level of the community and health personnel, health infrastructure, cooperation of related units and the determinant factors in the development of MDRTB (2,5-7). The rates of resistance to a single drug or a greater number of TB drugs vary according to societies and regions. Single drug resistance is reported as $20 \%$ and multiple drug resistance is reported as $10 \%$ in developing countries. This rate is even higher in patients who previously received TB treatment. For effective treatment, drug susceptibility tests, detection of resistant 
cases and initiation of second line antiTB drugs are of great importance in terms of treatment and prevention of spread of the disease (1,8-10).

Many new methods have been developed to accelerate the diagnosis of TB. These include radiometric methods, DNA probes, mycolic acid chromatography, PCR and serological tests $(11,12)$. Each country has to establish TB treatment programs according to epidemiological characteristics and requirements, prevalence of primary resistance, attitudes and behaviors of patients regarding TB treatment, health infrastructure and economic strength, and determine appropriate treatment regimens and methods of application for these different clinical situations. As a result of the studies, it has been shown that the clinical and epidemiology of TB has changed and resistance to multiple drugs has disrupted the efficacy of the regimens used in the treatment $(1,3,10)$. Innovations in molecular biology have opened new horizons in the diagnosis of $\mathrm{TB}$ cases and epidemiological studies. Today, geographic distribution maps of TB are made using molecular epidemiological typing methods such as spoligotyping, IS 6110-RFLP (Restriction fragment length polymorphysm), MIRU etc. This can give information about disease control, which different strains are present, their drug resistance status, and what precautions can be taken? (13-17).

In this study, it was aimed to determine the epidemiologic origins of MDR-TB strains isolated from different geographical regions by second line drug resistance profile and molecular epidemiologic methods (spoligotyping, IS6110 RFLP) by indirect proportion method.

\section{MATERIAL AND METHOD}

Ethics committee approval is not required for this study, as there is no study conducted on individuals or containing biological material.

\section{Patients and Bacterial Strains}

This study performed in collobaration between İnönü University Faculty of Medicine Departmant of Microbiology between November 2006 and November 2007. The study was carried out within the scope of TÜBİTAK SBAGHD63 project with the official permission of the Refik Saydam Hygiene Center. The 63 isolates used in the study consisted of MTB strains isolated from sputum samples taken from patients with suspected tuberculosis with clinical, symptomatic and radiological findings in Kayseri, Trabzon, İzmir, Elazığ, Denizli, Çorum and Ankara provinces of our country. A value above $15 \mathrm{~mm}$ was recorded in PPD confirmation tests of all patients, and positive results were obtained with AARB staining in smear tests. MDR-TB was detected in all patients according to the indirect proportion drug susceptibility test results. In the study (7) TB isolates, which were found to have multiple drug resistance from the isolates sent for external quality control in the sensitivity tests from the Supranational TB Laboratory (Roma, Italia), were evaluated as controls.

\section{Bacteriology and Drug Susceptibility Testing}

All patient specimens submitted for acid-fast culture were processed by the $\mathrm{N}$-acetyl- $\mathrm{L}$ cysteine- $\mathrm{NaOH}$ decontamination procedure recommended by the BACTECTM MGITTM 960 TB system manufacturer (Becton Dickinson) (18-20). Isolates grown in MGIT tube were also subcultured on Löwenstein Jensen (LJ) medium at $37^{\circ} \mathrm{C}$. Fresh cultures on LJ medium were used as a source of the organisms. Differentiation of the MTBC and non-TB mycobacteria were performed by BD MGIT $^{\text {tm }}$ TBC Identification Test. Testing for susceptibility to rifampicin (RIF), isoniazid (INH), streptomycin (SM), and ethambutol (EMB) was performed by the BACTECTM MGITTM 960 TB drug susceptibility test kit. Drug susceptibility testing against rifampicin (R), isoniazid (I), streptomycin (S), and ethambutol (E) was performed by using standard proportion method on LJ medium $(11,12)$.

\section{DNA Extraction}

A loopful of bacteria colonies was suspended in $400 \mu \mathrm{l}$ $1 \times$ TE buffer ( $10 \mathrm{mM}$ Tris, $1 \mathrm{mM}$ EDTA, $\mathrm{pH}$ 8.0), and inactivated at $80^{\circ} \mathrm{C}$ for 20 minutes. Bacterial DNA was extracted by the standard cetyl-trimethyl ammonium bromide (CTAB) (Merck, Darmstadt, Germany) method, as described previously. The pellet of DNA was dried at room temperature, resuspended in $1 \times \mathrm{TE}$ buffer and stored at $4^{\circ} \mathrm{C}$ until use (21).

\section{Molecular Typing}

Spoligotyping was performed by using a commercially available kit (Isogen Bioscience BV, Maarssen, The Netherlands) according to the instructions supplied by the manufacturer as previously described (26). The spoligotiyping method was performed according to manufacturer instructions $(27,28)$. The DNA concentration was estimated spectrophotometrically. The spacers between the direct repeats in the target region were amplified by using Dra biotinylated at the 5' and $\mathrm{DRb}$ primers. The amplified DNA was hybridized to a set of 43 immobilized oligonucleotides derived from the spacer sequences of $M$. tuberculosis $\mathrm{H} 37 \mathrm{Rv}$ and M. bovis BCG P3 by reverse line blotting. Detection of hybridizing DNA was done by enhanced chemiluminescence (ECL; Enhanced Chemo-Luminescence Detection kit; Amersham, Little Chalfont, England), followed by exposure to X-ray film (Hyperfilm ECL, Amersham), in accordance with the instructions of the manufacturer. M. tuberculosis strain $\mathrm{H} 37 \mathrm{Rv}$ and the Pasteur strain 
of $M$. bovis BCG P3 were used as reference strains for spoligotyping. The spoligotyping results were entered in a binary format as Excel spreadsheets and were compared to the World Spoligotype Database of the Institute Pasteur de Guadeloupe (29). An isolate was assigned a shared type if the same spoligotype was found for isolates obtained from two or more patients in the world. If no matching spoligotype was identified in the database, the isolate was defined as unique. The shared types formed by a unique isolate in the database and a Turkish isolate, or two or more Turkish isolate alone, were defined as new shared types. IS6110 RFLP was performed according to reference literatures (22-27).

\section{Statistical Analysis}

Descriptive statistics were calculated as count and percent. Spoligotyping and IS6110 RFLP typing test results were shared as cluster and group name.

\begin{tabular}{|c|c|c|}
\hline Drug & $\begin{array}{c}\text { \%1 CP için CC } \\
(\mu \mathrm{g} / \mathrm{ml})\end{array}$ & $\begin{array}{c}\text { \%10 CP için CK } \\
(\mu \mathrm{g} / \mathrm{ml})\end{array}$ \\
\hline İsoniazid & 0.2 & - \\
\hline Rifampicin & 40 & - \\
\hline PAS & 0.5 & 0.25 \\
\hline Cycloserine & 40 & 30 \\
\hline Etionamide & 30 & 20 \\
\hline Kanamycin & 30 & 20 \\
\hline Capreomycin & 40 & 20 \\
\hline Ofloxacin & 2 & - \\
\hline Tiasetozone & - & 10.0 \\
\hline
\end{tabular}

\section{Table 2. Second line drug resistance test results of MTB isolates}

\begin{tabular}{|lcc|}
\hline Drugs & \multicolumn{2}{c|}{ Isolates } \\
\cline { 2 - 3 } & Number & $\%$ \\
\hline Sensitive to all & 32 & 50.79 \\
Drug resistance & & \\
Resistant to only one drug & & 6.34 \\
Cycloserine (CYC) & 4 & 6.34 \\
Etionamide (ETN) & 4 & 3.17 \\
Capreomycin (CAP) & 2 & 4.76 \\
Tiasetozone (TIA) & 3 & 4.76 \\
Oflaxacin (OFL) & 3 & 6.34 \\
Kanamycin (KAN) & 4 & - \\
Paraaminosalicylic acid (PAS) & 0 & 31.74 \\
Total & 20 & \\
Resistant to only two drug & & 1.58 \\
ETN+KAP & 1 & 1.58 \\
TİA+OFL & 1 & 3.17 \\
CYC+ETN & 2 & 6.34 \\
Total & 4 & 1.58 \\
Resistant to only three drug & & 1.58 \\
ETN+KAP+KAN & 1 & 1.58 \\
ETN+KAN+PAS & 1 & 1.58 \\
SKS+OFL+PAS & 1 & 3.17 \\
KAP+KAN+PAS & 1 & 9.52 \\
SKS+ETN+OFL & 2 & 1.58 \\
Total & 6 & \\
Resistant to four drugs & & \\
SKS+ETN+KAN+PAS & 1 & \\
Total (Resistance) & & \\
& & \\
\hline
\end{tabular}

\section{RESULTS}

All 63 isolates used in this study were resistant to first line drugs rifampicin and isoniazid. The results of the second line drug susceptibility tests of these isolates are given in Table 2. According to the test results, 32 (50.79\%) of 63 isolates were susceptible to 7 minor drugs and $31(49.20 \%)$ were resistant to at least one drug. While 20 isolates were resistant to one drug $(31.74 \%)$, 4 were resistant to two drugs (6.34\%), 6 were resistant to three drugs $(9.52 \%)$ and $1(1.58 \%)$ to four drugs.

Of 63 isolates, 32 (50.79\%) were susceptible to 7 minor drugs and 31 (49.20\%) were resistant to at least one drug. Among the resistant isolates; While 20 isolates were resistant to one drug (31.74\%), 4 were resistant to two drugs $(6.34 \%), 6$ were resistant to three drugs $(9.52 \%)$ and $1(1.58 \%)$ to four drugs. No resistance was detected in all 7 drugs. When the resistance rate for each second line drug was evaluated in general, the highest resistance was found to be $12(19.04 \%)$ against etionamide and the lowest resistance to PAS in 4 isolates (Table 3 ).

The spoligotyping results of 63 isolates were shown in Table 4.

\section{Table 3. Number and percentage of 63 minor MDR-resistant}

strains found to be resistant to 7 second line antituberculosis drugs by indirect proportion method

\begin{tabular}{|lcc|}
\hline Drugs & $\begin{array}{c}\text { Number of } \\
\text { resistant strains }\end{array}$ & Percent (\%) \\
\hline Cycloserine (CYC) & 10 & 15.87 \\
Etionamide (ETN) & 12 & 19.04 \\
Capreomycin (CAP) & 5 & 7.93 \\
Tiasetozone (TIA) & 4 & 6.34 \\
Oflaxacin (OFL) & 7 & 11.11 \\
Kanamycin (KAN) & 8 & 12.69 \\
Paraaminosalicylic acid (PAS) & 4 & 6.34 \\
\hline
\end{tabular}

\section{Table 4. Spoligotypes of isolate clusters}

\begin{tabular}{|c|c|c|c|c|}
\hline Cluster & $\begin{array}{l}\text { Size of } \\
\text { cluster }\end{array}$ & $\begin{array}{l}\text { Isolates of } \\
\text { Percentage }^{\mathrm{a}}\end{array}$ & $\begin{array}{c}\text { Spoligotype } \\
\text { pattern }\end{array}$ & $\begin{array}{c}\text { Spoligotype } \\
\text { family }^{\mathbf{b}}\end{array}$ \\
\hline A & 1 & 1.58 & 760177777720771 & $\mathrm{H} 3$ \\
\hline B & 1 & 1.58 & 774777777420771 & $\mathrm{H} 4$ \\
\hline $\mathrm{C}$ & 1 & 1.58 & 776023037760771 & Orphan \\
\hline $\mathrm{D}$ & 1 & 1.58 & 777737774020771 & H1 \\
\hline $\mathrm{E}$ & 1 & 1.58 & 777737777760700 & $\mathrm{~T} 3$ \\
\hline $\mathrm{F}$ & 1 & 1.58 & 777777000437771 & Orphan \\
\hline G & 16 & 25.39 & 777777404760771 & LAM7-TUR \\
\hline $\mathrm{H}$ & 1 & 1.58 & 777777600760771 & $\mathrm{~T} 1$ \\
\hline I & 4 & 6.34 & 777777607760771 & LAM9 \\
\hline $\mathrm{J}$ & 1 & 1.58 & 777777637760771 & $\mathrm{~T}$ \\
\hline K & 1 & 1.58 & 777777760000731 & U \\
\hline $\mathrm{L}$ & 10 & 15.87 & 777777770000771 & $\mathrm{U}$ \\
\hline M & 1 & 1.58 & 777777774020771 & H1 \\
\hline $\mathrm{N}$ & 2 & 3.17 & 777777777720771 & H3 \\
\hline $\mathrm{O}$ & 20 & 30.15 & 777777777760771 & $\mathrm{~T} 1$ \\
\hline $\mathrm{P}$ & 1 & 1.58 & 777777777777400 & $\mathrm{BOV}$ \\
\hline
\end{tabular}


16 spoligotypes were detected by this method. Eleven isolates (17.46\%) formed separate spoligotype, 52 (82.53\%) isolates formed 5 clusters (G, I, L, N, O). Sixteen samples (cluster G) showing the same spoligotype were identified as the LAM-7 TUR spoligotype family. The largest spoligotype cluster (20 isolates, cluster 0 ) matched the T1 family. Four isolates in cluster J were identified as LAM 9 spoligotype. 2 isolates in cluster $\mathrm{N}$, 1 isolate in cluster B and 1 isolate in cluster are defined as Haarlem 3, Haarlem 4, Haarlem 1 spoligotype, respectively. The isolates (1 isolate) in clusters A and $M$ shared the key characteristics of the Haarlem family. Although 1 isolate in cluster $\mathrm{K}$ and 10 isolate in cluster $\mathrm{L}$ have characteristic spoligotip characteristics of $\mathrm{U}$ family, filling of 15-24 spacers in the $\mathrm{K}$ cluster and 25-32 spacers in the L cluster requires more detailed identification for the $\mathrm{U}$ family. One isolate in the $\mathrm{P}$ cluster showed the characteristic features of the $\mathrm{BOV}$ (Bovis) family with the absence of 33-43 spacers. The isolates ( 1 isolate) in clusters $\mathrm{C}$ and $\mathrm{F}$ were defined as orphan. $63 \mathrm{MDR}$ tuberculosis isolate was also genotyped by IS6110-RFLP method. No results were obtained due to low DNA concentration in 32 isolates. 3 clusters were formed in 31 isolates.

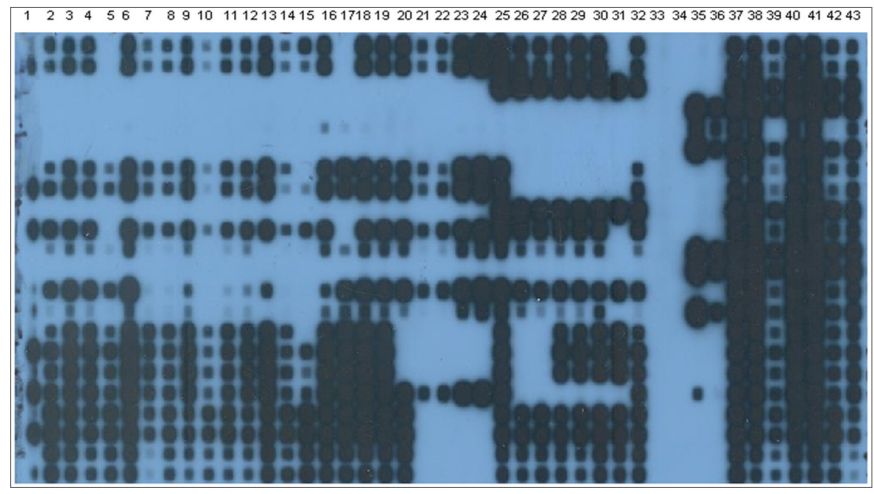

Figure 1. Evaluation of MTB isolates by spoligotyping method

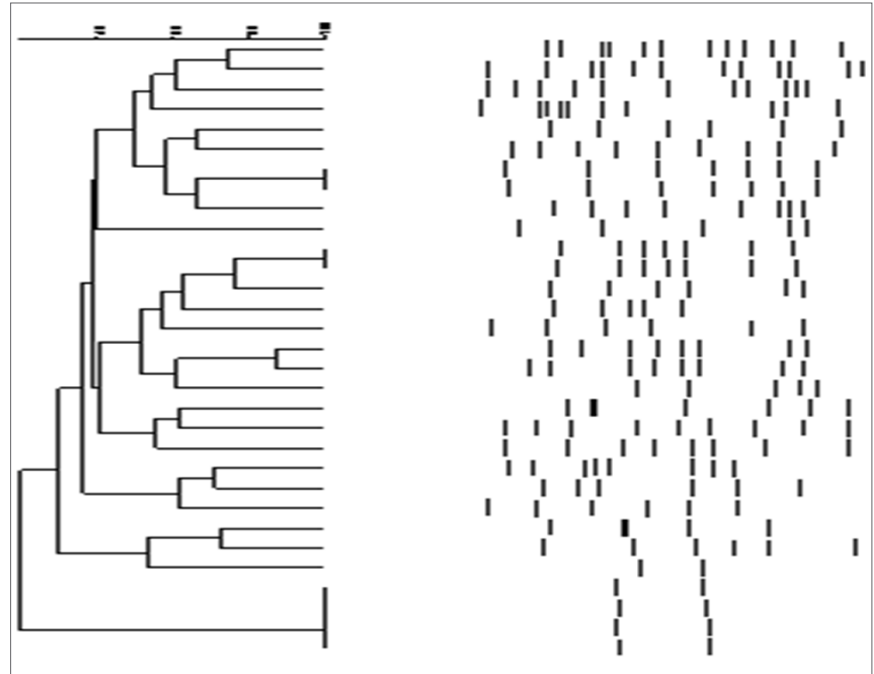

Figure 2. Evaluation of MTB isolates by IS 6110 RFLP method

\section{DISCUSSION}

Multi drug-resistant tuberculosis remains an important threat all over the World. It is the development of resistance to drugs used against the disease that presents $\mathrm{TB}$ as a problem for today and the future. The most important reason for this is treatment failure. Drug regimens were given to patients who were the result of insufficient TB control programs in the past and drugs were used unattended, causing drug resistance rates to increase. In the regulation of follow-up and treatment of patients, it is important to know the drug resistance rates in the community and to determine the individual resistance status. In the direction of Directly Observed Treatment (DOT) and DGT-plus (DOT-plus) strategies, which have been on the agenda in recent years, and due to the major and minor antiTB-resistant cases that are increasingly encountered in daily practice, drug susceptibility tests have become more important today, laboratory methods used to determine drug sensitivity and studies on this subject have been accelerated (1-5).

In Turkey, susceptibility tests to second generation drugs are carried out only in the National Tuberculosis Reference and Research Laboratory. Therefore, there are limited data on second line drug sensitivity rates. In most of the studies, only a few of these drugs were included in the study and it was not stated how much strains in these studies were MDR- MTB isolate.

In our study, the susceptibility of 63 multi-drug resistant MTB strains were isolated from different geographic regions to 7 minor antiTB drugs was determined according to the indirect proportion method in the LöwensteinJensen medium, which is accepted as the reference method. While $32(50.79 \%)$ of 63 isolates were sensitive to 7 minor drugs, $31(49.20 \%)$ were found resistant to at least one drug. In the evaluation made among the resistant isolates; while 20 isolates were resistant to one drug (31.74\%), 4 were resistant to two drugs (6.34\%), 6 to three drugs (9.52\%) and 1 (1.58\%) to four drugs. Among the isolates examined, resistance to 7 drugs was not detected. When the resistance rate for each minor drug is generally evaluated; resistance rates for CYC, ETN, CAP, TIA, OFL, KAN and PAS, respectively; $15.87 \%, 19.04 \%, 7.93 \%$, $6.34 \%, 11.11 \%, 12.69 \%$ and $6.34 \%$ were found. The highest resistance in our study was found in ETN (19.04\%).

In another study in the same center conducted by Kayalı et al. (28) ; second-line drug resistance rates for ETN, CYC, KAN, PAS,OFL, TIA, and CAP in a different set of MDR-TB samples were found as $22 \%, 8 \%, 6 \%, 6 \%$, $2 \%$, and $0 \%$, respectively. Our results were similar to this study.

Şimşek et al. (29) in their evaluation of 122 MDR MTB isolates using the E-test method; found that 119 (98\%) 
isolates were susceptible to CAN, OFL, ETN and linezolid (LIN), while $3(2 \%)$ were resistant to ETN and CAN. The Etest method is a standardized gradient method and is a more reliable test. The fact that our rates are higher may be due to the difference in method.

Second line drug susceptibility varies in different regions of the world, this situation is similar in Turkey.

Bektöre et al. (30) investigated the susceptibility status of $81 \mathrm{MDR}-\mathrm{TB}$ isolates isolated from MDR-TB patients living in Istanbul, Izmir and Manisa to first- and secondline anti-TB drugs with the fully automated BACTEC MGIT960 system; determined the rates of resistance to second-line anti-TB drugs as 1.2\% for Amikacin (AMK) and CAN, 2.5\% for OFL and levofloxacin (LVX), 14.8\% for CPM, 37\% for ETN, and did not detect resistance to LIN. ETN resistance rate in our study was found to be similar to this study.

There are studies showing that resistance to izoniazide (INH) associated with mutations in the inhA gene. Considering that the isolates studied are INH resistant, our conclusion supports this hypothesis. However, in our study, strains sensitive to etionamide were also detected. This suggests that INH resistance developing with other mechanisms does not cause resistance development against etionamide. In the study conducted by Çiçek et al. (31). With the method of probing in MB 7H10 agar for the detection of sensitivity against minor drugs in 100 strains of MTB, ethionamide resistance was found to be $4 \%$, but it was found that all strains of MTB, which are resistant to multi drug, are sensitive to ethionamide.

This situation can be explained by its role in different mechanisms in INH resistance. This rate is quite low compared to ETN resistance, which was found to be $19.04 \%$ in our study. This difference suggests that all MTB isolates used in our study may be due to the fact that they are MDR. The resistance rate we found in the strains of MDR- MTB against TIA is $6.34 \%$.

The most studied secondline antiTB drug in our country is TIA. In the first studies carried out by the national reference center in our country; Tumer and Savran (32) used the properation method to determine the resistance to TIA. While $8 \%$ of 2345 strains of MTB were found to be resistant to TIA in 1992, this ratio was found to be $6 \%$ in 1639 isolates in 1993. Osmanlığlu (33) determined the average resistance to TIA as $8 \%$ in cultures sent to the RSHMB tuberculosis national reference laboratory in 1990 from all regional TB laboratories. However, no information is given about the extent to which these origins are MDR- MTB. In a study conducted by Kayalı (28), while 50 MDR-MTB isolates were found to be $2 \%$ in TIA resistance by the method of proportions, this rate was higher in our study (6.34\%). In this study, resistance to OFL was determined as $11.11 \%$. The development of cross resistance among the commonly used quinolone group antibiotics can be held responsible for this situation. Özkütük et al. (34) found 5\% OFL resistance in their studies evaluating $40 \mathrm{MDF}-\mathrm{TB}$ strains with BACTEC 460 TB radiometric semi-automated culture system.

In our study, the $11.11 \%$ resistance we found in MDR -MTB isolates suggests that quinolones may be developed as a result of the empirical starting of quinolones in patients with $\mathrm{TB}$ over time. The rate of resistance to PAS was found to be $6.34 \%$. Çiçek et al. (31) found 12\% resistance for PAS. Strains of MDR -MTB were found to be sensitive to PAS. In this study, the resistances of CYC, CAP and CAN were found as $15.87 \%, 7.93 \%$ and $12.69 \%$, respectively. Pfyffer et al. (35) conducted a three-phase study in 1999. While phase I had strains sensitive to all drugs, phase 2 had strains known to be susceptible and resistant to drugs, and phase 3 had a large working group, mostly composed of resistant strains. Resistance to CYC was found to be $7.85 \%$ in phase 3 . In the same study, resistance to CAN and CAP was $45 \%$ and $30 \%$ in phase 2 , respectively; found to be $8.26 \%$ in phase 3 . The values we detected in our study are higher.

Since TB is a highly contagious and drug resistant disease, it requires better surveillance programs and a rapid diagnosis of the disease. It is thought that there are geographical differences in terms of epidemiological differences between strains. In epidemiological studies, comparing the strains isolated from different geographic regions with each other and monitoring individual strains, It suggests that strains associated with transmission routes, high virulence and multiple drug resistance can be detected worldwide (36).

With the introduction of molecular methods to routine use, epidemiology studies have become easier. Typing of bacterial strains, TB prevalence and spread are the most important topics studied. In studies conducted with spoligotyping and IS6110 methods, MTB isolates were sensitively typed $(37,38)$.

Thanks to the data obtained from these studies, it is planned to establish treatment protocols quickly and control the disease according to the epidemiological origin. In this study, epidemiological origins of strains of 63 MDR-TB isolates sent from different geographical regions (Kayseri,Trabzon, İzmir, Elazı̆̆, Denizli, Çorum, Ankara) of Turkey were investigated by spoligotyping and IS6110 RFLP method.

No results were obtained due to low DNA concentration in 32 isolates. 3 clusters were formed in 31 isolates. All isolates were studied by spoligotiping method to better identify clusters of related strains. Spoligotyping was used as the second method, especially in strains with 6 
or fewer copies of IS6110. The spoligotypes of the two samples detected by two bands with IS6110 method were the same. The combined use of the two methods reduced the fraction of clustered strains.

In this study, the percentage of clusters we determined using the IS6110 and spoligotiping method was found to be similar to the clusters recently characterized by the combination of IS6110 and pTBN12 fingerprint methods. 16 spoligotype were determined by spoligotiping method. 11 isolates (17.46\%) were separate spoligotip and 52 $(82.53 \%)$ isolates formed 5 clusters. Sixteen samples showing the same spoligotype were from the LAM-7 TUR spoligotip family. The largest spoligotip cluster matched the T1 subset. 4 isolates were identified as LAM 9 spoligotype. Two isolates were defined as Haarlem 3, 1 isolate Haarlem 4, 1 isolate Haarlem 1 spoligoty. Two isolates shared key characteristics of the Haarlem family. Although the $11 \mathrm{U}$ family has the characteristic spoligotip features, the exact definition needs to be confirmed by the world database.In our study, the LAM-7 TUR spoligotip family unique to our country was identified. The data obtained from our study showed compatibility with other similar studies conducted in our country (39-46).

$\mathrm{U}$ family is a spoligotip defined in Eastern Europe and especially in Russia according to Spol4B program 64 . The fact that it belongs to the province of Trabzon in 11 isolates supports that it will belong to the spoligotip $U$ family determined in this group due to its geographical proximity. In our study, while 1 isolate showed the character characteristics of the BOV family, 2 isolates were found to be orphan (47).

In a study recently reported by Karagöz et al. (39) in our country; 13 different spoligotypes were defined by the spoligotyping method, and a total of 188 strains (94.0\%) were included in the cluster. The most prominent spoligo family was the $\mathrm{T}$ family ( $43.0 \%$ of the strains). The other group consisted of LAM (26.0\%), H (8.0\%), X and S (both $6.0 \%$ ), and $U$ (5.0\%). The study also found a Beijing profile of $6.0 \%$.

In another study in Turkey, Cavusoğlu et al. (48) were investigated genotype distribution of $M$. tuberculosis in Aagean region in $470 \mathrm{M}$. tuberculosis isolates from 470 patients in 1996-2014. In this study, they reported that among the $470 \mathrm{M}$. tuberculosis strains, 132 different spoligopatterns were identified and 46 different cluster for 384 strains were determined. The most predominant spoligotypes were determined as $\mathrm{T} 1(\mathrm{n}: 116,24.7 \%)$, and LAM7-TUR (n:38, 8.1\%) followed by H3 (5.7\%), $\mathrm{T} 1(4.7 \%)$ and Unknown (4.3\%), respectively. MDR -TB was determined in 12 isolates, of which six were Beijing.

In our study, similar results were obtained with these studies.
The limitation of this study is that comprehensive studies with more samples are needed to identify definitive epidemiological groups across the country.

\section{CONCLUSION}

As a result; control and treatment of MTB infections is critical worldwide. Mapping of isolated strains according to geographical regions is important for controlling the disease and knowing whether the disease is an infection or reactivation.

At this stage, epidemiological studies are valuable. It is concluded that it would be beneficial to carry out these studies with internationally accepted methods that determine the genotype of the strains. Extensive studies with more isolates are needed to assess the effectiveness and transmission of the tuberculosis control strategy. In susceptibility tests, the factors of the method used can affect the results. The main differences are in practice differences, inoculum amount, medium used and drug concentrations. Therefore, it is not possible to talk about complete standardization in comparing the results obtained in different centers. Despite this, studies can have information about resistance rates in different regions.

\section{ETHICAL DECLARATION}

Ethics Committee Approval: Ethics committee approval is not required for this study, as there is no study conducted on individuals or containing biological material.

Informed Consent: There is no need for informed consent since there is no study on individuals or containing biological material.

Referee Evaluation Process: Externally peer-reviewed.

Conflict of Interest Statement: The authors have no conflicts of interest to declare.

Financial Disclosure: This study was supported by TUBITAK Health Sciences Research Group (SBAG) numbered SBAG-HD-63(105S321)

Author Contributions: All of the authors declare that they have all participated in the design, execution, and analysis of the paper and that they have approved the final version.

\section{REFERENCES}

1. WH0. Global tuberculosis report 2019. Geneva: World HealthOrganization, 2020. https: //www.who.int/tb/publications/ global_report/en/

2. WHO Consolidated Guidelines on Tuberculosis Module 4: Treatment Drug-resistant Tuberculosis Treatment. Geneva, World Health Organization, 2020. https: //apps. who.int/iris/ bitstream/handle/10665/332397/9789240007048-eng.pdf

3. World HealthOrganization. Guidelines for the programmatic management of drug-resistant tuberculosis-2014. 
4. McBryde ES, Meehan MT, Doan TN, et al. The risk of global epidemic replacement with drug resistant $M$. tuberculosis strains. Int J Infect Dis 2017; 56: 14-20.

5. Dheda K, Gumbo T, Maartens G, et al. The epidemiology, pathogenesis, transmission, diagnosis, andmanagement of multidrug-resistant, extensively drug-resistant, and incurable tuberculosis. Lancet Respir Med 2017; 5: 291-360.

6. Suchindran S, Brouwer ES, Van Rie A. Is HIV infection a risk factor for multi-drug resistant tuberculosis? A systematic review. PLoS One 2009; 4: e5561.

7. Kendall EA, Fofana MO, Dowdy DW. Burden of transmitted multidrug resistance in epidemics of tuberculosis: a transmission modelling analysis. Lancet Respir Med 2015; 3: 963-72.

8. Uçar E, Kılıç A, Ceyhan I, et al. Ülkemizin yedi farklı bölgesinden 2003-2006 yilları arasinda izole edilen Mycobacterium tuberculosis suşlarının majör antitüberküloz ilaçlara direnç oranları. Mikrobiyol Bült 2010; 44: 11-9.

9. Türkiye'de Verem Savaş Raporu 2019. T.C. Sağlık Bakanlığg Halk Sağlığı Genel Müdürlüğü, 2019.

10. World Health Organization WHO treatment guidelines for drugresistant tuberculosis 2016 update. WHO/HTM/TB 2016. 04. World Health Organization, Geneva, 2016.

11. Handbook on TB laboratory diagnostic methods in the European Union. Technical Document.https: //www.ecdc.europa.eu/ sites/ default/ files/ documents/ tuberculosis - laboratory-diagnosticmethods-eu.pdf.2016.

12. Ulusal Tüberküloz Tanı Rehberi. T.C. Sağlık Bakanlığı Türkiye Halk Sağlığı Kurumu Başkanlığı Mikrobiyoloji Referans Laboratuvarları Daire Başkanlığı Ankara - 2014.

13. Basil MV, Nair D. Molecular epidemiology of tuberculosis: Opportunities\&challenges in disease control. Indian J Med Res 2017; 146: 11-14.

14. Cannas A, Mazzarelli A, DiCaro A, Delogu G, Girardi E. Molecular typing of Mycobacterium tuberculosis strains: A fundamental tool for tuberculosis control and elimination. Infect Dis Rep 2016; 8: 6567.

15. Jagielski T, Minias A, vanIngen J, et al. Methodological and clinical aspects of the molecular epidemiology of Mycobacterium tuberculosis and other mycobacteria. Clin Microbiol Rev 2016; 29: 239-90.

16. Oudghiri A, Chaoui I, Elmzibri M. Molecular epidemiology of tuberculosis: a review of tools and applications. J InfectDis Ther 2018; 6: 386 .

17. Kato-Maeda M, Metcalfe JZ, Flores L. Genotyping of Mycobacterium tuberculosis: application In epidemiologic studies. Future Microbiol 2011; 6: 203-16.

18. Kubica GPW, Dye E, Cohn ML, Middlebrook G. Sputum digestion and decontamination with N-acetyl-L-cysteinesodiumhydroxide for culture of mycobacteria. Am Rev Respir Dis 1993; 87: 775-80.

19. Becton Dickinson. MGIT For BACTEC ${ }^{\mathrm{Ts}}$ MGIT $960^{\mathrm{Tm}}$ TB System 2006

20. Kim SJ. Drug-susceptibility testing in tuberculosis: methods and reliability of results.Eur Respir J 2005; 25: 564-9.

21. Kocagöz T, Yılmaz E, Özkara Ş, et al. Detection of Mycobacterium tuberculosis in sputum samples by polymerase chain reaction using a simplified procedure. J Clin Microbiol 1993; 31: 1435-8.

22. van Soolingen D, Hermans PW, de Haas PE, Soll DR, van Embden JD. Occurrence and stability of insertion sequences in Mycobacterium tuberculosis complex strains: evaluation of an insertion sequence-dependent DNA polymorphism as a tool in the epidemiology of tuberculosis. J Clin Microbiol 1991; 29: 2578-86.

23. Kamerbeek J, Schouls L, Kolk A, et al. Simultaneous detection and strain differentiation of Mycobacterium tuberculosis for diagnosis and epidemiology. J Clin Microbiol 1997; 35: 907-14.
24. Aranaz A, Liebana E, Mateos A, Dominguez L, Cousins D. Restriction fragment length polymorphism and spacer oligonucleotide typing: a comparative analysis of fingerprinting strategies for Mycobacterium bovis. Vet Microbiol 1998; 61: $311-24$.

25. www.pasteur-guadeloupe.fr: 8081/sitvit_online

26. Roring S, Brittain D, Bunschoten AE, et al. Spacer oligotyping of Mycobacterium bovis isolates compared to typing by restriction fragment length polymorphism using PGRS, DR and IS6110 probes. Vet Microbiol 1998; 61: 111-20.

27. Sola C, Horgen L, Maisetti J, Devallois A, Goh KS, Rastogi N. Spoligotyping followed by double-repetitive-element PCR as rapid alternative to IS6110 fingerprinting for epidemiological studies of tuberculosis. J Clin Microbiol 1998; 36: 1122-4.

28. Kayalı R, Çöplü N, Ceyhan I, Ocak F, Çitil BE, Esen B. Çok ilaca dirençli Mycobacterium tuberculosis suşlarının minör antitüberküloz ilaçlara duyarlılı̆̆ının saptanması. Mikrobiyol Bült 2006, 40: 1-7.

29. Şimşek H, Tarhan, G, Cesur S. Evaluation of second-line antituberculosis drug susceptibilities of multidrug-resistant Mycobacterium tuberculosis complex isolates by E-test method. Mikrobiyol Bult 2015; 49: 47-55.

30. Bektöre B, Haznedaroğlu T, Baylan O, et al. Investigation of Extensive Drug Resistance in Multidrug Resistance Tuberculosis Isolates. Mikrobiyol Bul 2013; 47: 59-70.

31. Çiçek SC, Çavuşoğlu C, Burhanoğlu D, Özkalay N, Badak ZF, Bilgiç A. Susceptibility of Mycobacterium tuberculosis strains to first-line and second-line antituberculosis drugs in Ege University hospital. Turk J Med Sci 2001; 31: 395-400.

32. Tumer F, Savran Ş. Memleketimizde 1992-93 yıllarında tüberküloz ilaçlarına direnç durumu 20. Turk tüberküloz ve göğüs hastalıkları kongresi 7-9 Nisan 1994 Antalya, 380-386.

33. Osmanlığlu G. Türkiye’de tüberküloz ilaçlarında direnç durumu 19. Tüberküloz ve gögüus hastalıkları kongresi. Sivas, 1991; 158.

34. Ozkutuk N, Surucuoglu S, Gazi H, Coskun M, Ozkutuk A Ozbakkaloglu B. Second-line drug susceptibilities of multidrugresistant Mycobacterium tuberculosis isolates in AegeanregionTurkey. Turk J Med Sci 2008; 38: 245-50

35. Pfyffer EG, Bonato AD, Ebrahimzadeh A et al. Multicenter laboratory validation of susceptibility testing of Mycobacterium tuberculosis against classical second-line and newer antimicrobial Drugs by using the radyometric BACTEC 460 Technique and the proportion Method with Solid media. Clin Microbiol 1999; 37: 3179-86.

36. WH0. Guidelines for surveillance of drug resistance in tuberculosis. $5^{\text {th }}$ Edition, Geneva: World Health Organization, 2015.

37. Cannas A, Mazzarelli A, DiCaro A, Delogu G, Girardi E. Molecular typing of Mycobacterium tuberculosis strains: a fundamental tool for tuberculosis control and elimination. Infect Dis Rep 2016; 8: 6567.

38. Basil MV, Nair D. Molecular epidemiology of tuberculosis: Opportunities \& challenges in disease control. Indian J Med Res 2017; 146: 11-4.

39. Karagöz A, Hidayet Tütün H, Altintaş L, Alanbayi U, Yıldırım D, Kocak N. Molecular typing of drug-resistant Mycobacterium tuberculosis strains from Turkey. J Glob Antimicrob Resist 2020; 23: $130-4$.

40. Pourostadi M, Rashedi J, Poor BM, et al. Role of Molecular Epidemiology on Tuberculosis Control in the Middle East Countries: a Systematic Review and Meta-Analysis.Tanaffos 2018; 17: 223-32

41. Kisa O, Tarhan,G, Gunal S, et al. The distribution of spoligotyping defined genotypic lineages among drug-resistant $M$. tuberculosis complex clinical isolates in Ankara, Turkey, Plos One 2012; 7: e30331. 
42. Durmaz R, Ozerol IH, Durmaz B, Gunal S, Senoglu A, Evliyaoglu E. Primary drugresistance and molecular epidemiology of Mycobacterium tuberculosis isolates from patients in a population with high tuberculosis incidence in Turkey. Microb Drug Resist 2003; 9: 361-6.

43. Gencer B, Shinnick MT. Molecular genotyping of Mycobacterium tuberculosis Isolates from Turkey. Am J Infec Dis.2005; 1: 5-11.

44. Durmaz R, Zozio T, Gunal S, Allix C, Fauville-Dufaux M, Rastogi N. Population-based molecular epidemiological study of tuberculosis in Malatya. Turk J Clin Microbiol 2007; 45: 4027-35.

45. Durmaz R, Zozio T, Gunal S, et al. Genetic diversity and major spoligotype families of drug-resistant Mycobacterium tuberculosis clinical isolates from different regions of Turkey. Infect Genet Evol 2007; 7: 513-9.

46. Otlu B, Durmaz R, Gunal S, et al. Beijing/W and major spoligotype families of Mycobacterium tuberculosis strains isolated from tuberculosis patients in Eastern Turkey. New Microbiol 2009; 32: 255-63.

47. Sinkov V, Ogarkov O, Mokrousov I, Bukin Y, Zhdanova S, Heysell SK. New epidemic cluster of pre-extensively drug resistant isolates of Mycobacterium tuberculosis Ural family emerging in Eastern Europe. BMC Genomics 2018; 19: 762.

48. Cavuşoğlu C, Yılmaz FF, Onmus IRD, Bozdemir T, Taslı H, Limoncu MH. Genotype distribution of Mycobacterium tuberculosis in the Aegean Region and associated demographic factors. Turk J Med Sci 2017; 47: 1593-601. 